\title{
Late Pleistocene-dated divergence between South Hemisphere populations of the non-conventional yeast $L$. cidri.
}

\author{
Pablo Villarreal ${ }^{1}$, Carlos Villarroel ${ }^{2}$, Samuel O’Donnell ${ }^{3}$, Nicolas Agier ${ }^{3}$, Julian \\ Quintero-Galvis ${ }^{4}$, Tomas Peña ${ }^{1}$, Roberto Nespolo ${ }^{4}$, Gilles Fischer ${ }^{3}$, Cristian Varela ${ }^{5}$, and \\ Francisco Cubillos ${ }^{1}$ \\ ${ }^{1}$ Universidad de Santiago de Chile \\ ${ }^{2}$ Millennium Institute for Integrative Biology (iBio) \\ ${ }^{3}$ Sorbonne Universite \\ ${ }^{4}$ Universidad Austral de Chile \\ ${ }^{5} \mathrm{AWRI}$
}

January 10, 2022

\begin{abstract}
Most organisms belonging to the Saccharomycotina subphylum have high genetic diversity and a vast repertoire of metabolisms and lifestyles, which explains its ecological versatility. The yeast Lachancea cidri is an ideal model for exploring the interplay between genetics, ecological function and evolution. L. cidri is a species that diverged from the Saccharomyces lineage before the whole-genome duplication and exhibits a broad distribution across the South Hemisphere, thus displaying an important ecological success. Here, we applied phylogenomics to investigate the adaptive genetic variation of $L$. cidri isolates obtained from natural environments in Australia and South America. Our approach revealed the presence of two main lineages according to their geographic distribution (Aus and SoAm). Estimation of the divergence time suggest that South American and Australian lineages diverged near the last glacial maximum event during the Pleistocene (64-8 KYA), consistent with the presence of multiple glacial refugia. Interestingly, we found that the French reference strain belongs to the Australian lineage, with a recent divergence (405-51 YA), likely associated to human movements. Additionally, species delimitation analysis identified different evolutionary units within the South American lineage and, together with parameters like Pi $(\pi)$ and FST, revealed that Patagonia contains most of the genetic diversity of this species. These results agree with phenotypic characterizations, demonstrating a greater phenotypic diversity in the South American lineage. These findings support the idea of a Pleistocenedated divergence between South Hemisphere lineages, where the Nothofagus and Araucaria ecological niches likely favored the extensive distribution of L. cidri in Patagonia.
\end{abstract}

\section{INTRODUCTION}

Evaluating the genetic diversity of non-model species is essential for obtaining a thorough understanding of biodiversity and for analyzing the complexity of genotype-phenotype relationships in nature (Fournier et al., 2017). In this sense, microorganisms are particularly important since they represent a great proportion of the ecosystem's biomass and provide several ecosystem services such as foods, fuel, and nitrogen fixation capacity (Chen et al., 2019; Mirza et al., 2014). Particularly important are organisms belonging to theSaccharomycotina subphylum (yeasts), many of which have been domesticated for human benefit, showing great capacity for rapid evolution. Yeasts have small genome sizes, high genetic variation, and a wide repertoire of metabolisms and lifestyles, representing an ideal group of model and non-model organisms for phylogenomics and population genomics studies (Peter and Schacherer, 2016). However, most phylogenomic studies focused on Saccharomyces species and to a lesser extent on other genera like Candida or Lachancea 
, ignoring the overwhelming biodiversity in the Saccharomycotinasubphylum (Almeida et al., 2015; Gallone et al., 2016; Goncalves et al., 2016; Liti et al., 2009). In this context, different phylogenomic studies have provided new evidence on the evolutionary history of non-conventional yeast species and the genetic basis of their phenotypic diversity (Cadez et al., 2019; Friedrich et al., 2012; Vakirlis et al., 2018; Vakirlis et al., 2016). The ecology and evolution of species such as Candida albicans (Ford et al., 2015; Hirakawa et al., 2015), Candida glabrata (Gabaldon and Fairhead, 2019),Cryptococcus neoformans (Passer et al., 2019),Hanseniaspora uvarum (Guaragnella et al., 2019),Brettanomyces bruxellensis (Gounot et al., 2020) andLachancea kluyveri (Friedrich et al., 2015) is becoming known just recently, demonstrating unique phylogenetic distributions in each case.

A particularly intriguing group of species are the Lachanceacluster (Porter et al., 2019a). The genus was initially proposed in 2003 by Kurtzman P. (Kurtzman, 2003), which diverged from theSaccharomyces linage prior to the ancestral whole-genome duplication (WGD), 100 or more MYA (Hranilovic et al., 2017). The WGD event represents the key evolutionary innovation that diversified fermentative yeasts, thanks to the capacity of exploiting simple sugars in the ecological niche, an available hallmark in yeast after the appearing of angiosperms (Dashko et al., 2014; Nespolo et al., 2020a; Piskur et al., 2006). Thus, Lachancea yeasts would represent a basal lineage lacking this enhanced capacity, but still being able to consume sugars and ferment under aerobic conditions (Hagman et al., 2014).

Lachancea species harbor eight chromosomes and exhibit high levels of synteny in the coding regions (Porter et al., 2019b). However, chromosome sizes and nucleotide diversity differ significantly between species (Lachance and Kurtzman, 2011) and there is higher genetic diversity and genetic distance between Lachancea species compared to Saccharomyces (Vakirlis et al., 2016). Lachanceaspecies have been recovered from a wide variety of ecological niches, ranging from plants (Esteve-Zarzoso et al., 2001; Gonzalez et al., 2007; Romano and Suzzi, 1993a, b), tree barks (Nespolo et al., 2020b; Villarreal et al., 2021), tree exudates (Varela et al., 2020), insects (Phaff et al., 1956), soil (Lee et al., 2009; Mesquita et al., 2013), water (Kodama and Kyono, 1974) as well as food and beverages (Magalhães et al., 2011; Marsh et al., 2014; Nova et al., 2009; Pereira et al., 2011; Tzanetakis et al., 1998; Wojtatowicz et al., 2001). Despite the large number of ecosystems where Lachancea spp. are present, we still lack information concerning the genetic and genomic adaptations needed to survive in such a range of ecological niches (Porter et al., 2019b). In this sense, the number of currently availableLachancea genomes is still low, and therefore most species remain unexplored.

The availability of complete genomes of many individuals is a prerequisite for exploring the diversity and genomic structure of a species. Thus far, genomic studies have been carried out in Lachancea thermotolerans , L. fermentati, and L. kluyveri, contributing to a better understanding of the population structure, ecology, and evolution of these species (Porter et al., 2019b). L. thermotolerans is the best-studied species of the genus (Banilas et al., 2016; Hranilovic et al., 2017; Hranilovic et al., 2018), and it has been reported that the evolution of $L$. thermotolerans was driven by geographic isolation and local adaptation (Hranilovic et al., 2017). Furthermore, these species possess an attractive biotechnological potential to produce new fermented beverages, where the biotransformation of organic acids provides a novel sensory profile and mouthfeel in the beverage (Hranilovic et al., 2018; Morata et al., 2018). Nonetheless, studies related to the natural population diversity, evolution, and biotechnological potential of other species of the genus are still scarce, mainly due to the low number of isolates sampled to date.

Recently, L. cidri was recovered from cider fermentations in Europe, eucalyptus tree sap in Australia and from Nothofagus forests in Patagonia. The isolates exhibit an interesting phenotypic diversity and biotechnological potential for wine and mead fermentations (Nespolo et al., 2020b; Villarreal et al., 2021). Patagonian $L$. cidri isolates showed a greater fitness in high throughput microcultivation assays for fermentative-related conditions, such as growth under different carbon sources (fructose, glucose, and maltose), together with high ethanol tolerance $(6$ and $8 \% \mathrm{v} / \mathrm{v})$. Interestingly, microfermentations in different musts demonstrated the potential of $L$. cidri in mead, surpassing the fermentative capacity of commercial $S$. cerevisiaestrains, together with providing a distinctive organoleptic profile to the final ferment, mostly because of the production of acetic and succinic acid (Villarreal et al., 2021). However, the phenotypic diversity (and the underpinning 
genetic variation) of this species has not been determined. The broad global distribution of $L$. cidrirepresents an excellent opportunity to establish the ecological and geographic determinants of the actual distribution of a non-conventional yeast (Porter et al., 2019a, b; Villarreal et al., 2021).

In order to address this problem, we characterized the genomic and phenotypic profiles of 55 L .cidri strains. The isolates were collected from the bark ofNothofagus and Araucaria trees in Chile and from sap samples of Eucalyptus gunni in Australia, together with a single isolate from cider fermentations from France. Overall, we demonstrate that Patagonia represents a natural and unique reservoir of genetic and phenotypic diversity for the species, mainly due to the broad and varied environments it provides (both spatially and temporally). Then, our results increased the number of evolutionary units of Lachancea,extending our current knowledge of the genetics, ecology and biotechnological potential of this novel natural resource from Patagonia.

\section{METHODS}

\section{Sample area, yeast isolation, and $L$. cidriidentification.}

Sampling was performed as previously described (Sampaio and Goncalves, 2008) in twelve locations in Chile (Table S1). Briefly, bark samples were collected aseptically from Nothofagus pumilio ,Nothofagus dombeyi , Nothofagus antartica andAraucaria araucana trees, and incubated in $10 \mathrm{~mL}$ enrichment media (2\% yeast nitrogen base, $1 \%$ raffinose, $2 \%$ peptone and $8 \%$ ethanol) (Sampaio and Goncalves, 2008). After 10 days, $5 \mu \mathrm{L}$ were streaked onto YPD (1\% w/v yeast extract, $2 \% \mathrm{w} / \mathrm{v}$ peptone, $2 \% \mathrm{w} / \mathrm{v}$ glucose $)$ agar and isolated colonies were stored in $20 \% \mathrm{v} / \mathrm{v}$ glycerol at $-80^{\circ} \mathrm{C}$. L . cidri isolates were determined by amplification and sequencing of the internal transcribed spacer region (ITS1-5.8rRNA-ITS2 ) using universal fungal primers, ITS-1 5'-TCCGTAGGTGAACCTGCGG-3' and ITS-4 5'-TCCTCCGCTTATTGATATGC-3'. Genomic DNA was extracted from 5 -mL cultures grown overnight in YPD media with shaking at $20^{\circ} \mathrm{C}$, using $50 \mathrm{mg} \mathrm{mL}^{-1} \mathrm{Zymo-}$

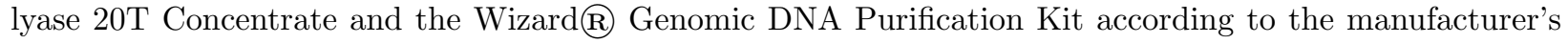
instructions. Polymerase Chain Reactions (PCR) were performed in a final volume of $10 \mu \mathrm{L}$ containing 0.2 $\mu \mathrm{L} 10 \mathrm{mg} \mathrm{mL} \mathrm{m}^{-1} \mathrm{BSA}$ (Promega), $3.5 \mu \mathrm{L}$ 2X GoTaq® Colorless Master Mix, $0.6 \mu \mathrm{L} 10 \mu \mathrm{M}$ ITS1 primer, $0.6 \mu \mathrm{L} 10 \mu \mathrm{M}$ ITS4 primer, $1 \mu \mathrm{L}$ diluted DNA $\left(10 \mathrm{ng} \mu \mathrm{L}^{-1}\right)$ and $4.1 \mu \mathrm{L}$ nuclease-free water (Fujita et al., 2001). PCR amplifications were performed in a T100 Thermal Cycler thermocycler (BioRad) as follows: initial denaturation at $94^{\circ} \mathrm{C}$ for $5 \mathrm{~min}$, then 35 cycles of denaturation at $94^{\circ} \mathrm{C}$ for $1 \mathrm{~min}$, annealing at $55^{\circ} \mathrm{C}$ for $2 \mathrm{~min}$, and extension at $72^{\circ} \mathrm{C}$ for $2 \mathrm{~min}$; followed by a final extension at $72^{\circ} \mathrm{C}$ for $5 \mathrm{~min}$. To determine the ITS 1-5.8SrRNA-ITS 2 PCR amplicon size, reaction products were analyzed in a $2 \%(\mathrm{w} / \mathrm{v})$ agarose gel by electrophoresis. ITS sequencing was performed in an Applied Biosystems 3500 instrument (AustralOmics, Valdivia, Chile). Additionally, $25 \mathrm{~L}$. cidriisolates were obtained from tree sap samples of Eucalyptus gunniifrom the Central Plateau of Tasmania, Australia (Varela et al., 2020). The isolates obtained and their geographical locations are listed in Table S1.

\section{FACS analysis}

DNA content was analysed using the propidium iodide (PI) staining assay. Cells were first recovered from the glycerol stocks on YPD solid media and incubated overnight at $30 \mathrm{degC}$. The following day, a fraction of each patch was taken with a pipette tip, transferred into liquid YPD media, and incubated overnight at 30 degC. Then, $1 \mathrm{~mL}$ of each culture was taken and resuspended in $2.3 \mathrm{~mL}$ cold $70 \%$ ethanol. Cells were fixed overnight at $4 \mathrm{degC}$, washed twice with PBS, resuspended in $100 \mu \mathrm{L}$ staining solution $(15 \mu \mathrm{M} \mathrm{PI}, 100 \mu \mathrm{g}$ $\mathrm{mL}^{-1}$ RNase A, $0.1 \% \mathrm{v} / \mathrm{v}$ Triton-X, in PBS) and finally incubated for $3 \mathrm{~h}$ at $37^{\circ} \mathrm{C}$ in the dark. Ten thousand cells for each sample were analysed on a FACS-Calibur flow cytometer. Cells were excited at $488 \mathrm{~nm}$ and fluorescence was collected with an FL2-A filter. Three strains with known ploidy were used as a control: Two S. euabaynus (n and $2 \mathrm{n}$ ) and one $S$. cerevisiae $(4 \mathrm{n})$.

\section{Whole-genome sequencing and Variant Calling.}

Genomic DNA from L. cidri colonies was prepared for whole-genome sequencing using a Qiagen Genomic-tip 20/G kit (Qiagen, Hilden, Germany) as previously described (Nespolo et al., 2020b) and sent for sequencing using DNBseq technology (BGISEQ-G400 platform) (Liu et al., 2018). Read quality was checked using 
FastQC 0.11.8 (Andrews, 2010). Reads were processed with fastp 0.19.4 (low quality 3' end trimming, 40 bp minimum read size) (Brickwedde et al., 2018; Chen et al., 2018). We also obtained publicly available sequencing reads of $L$. cidri CBS2950 (Agier et al., 2018), which were processed identically. Reads were aligned against the L. cidri CBS2950 reference genome (Vakirlis et al., 2016) using BWA-mem (options: -M -R) (Li, 2013). Mapping quality and overall statistics were collected and examined with Qualimap (Garcia-Alcalde et al., 2012). Sorting and indexing of output bam files were performed using SAMTOOLS 1.9 (Li et al., 2009). A L. fermentai isolate (CBS770) was also mapped against the L. cidriCBS2950 genome for phylogenetic analysis (Bellut et al., 2020). Mapping files were tagged for duplicates using MarkDuplicates of Picard tools 2.18.14 (http://broadinstitute.github.io/picard/). Variant calling and filtering were done with GATK version 4.0.10.1 (DePristo et al., 2011). More specifically, variants were called per sample and chromosome using HaplotypeCaller (default settings), after which variant databases were build using GenomicsDBImport. Genotypes for each chromosome were called using GenotypeGVCFs (-G StandardAnnotation). Variant files were merged into one genome-wide file using MergeVcfs. This file was divided into SNP calls and INDEL calls using SelectVariants. We applied recommended filters for coverage ( $>10$ mapping reads $=$ "FORMAT/DP > 10") and quality (-minQ 30) (Van der Auwera et al., 2013b). This VCF file was further filtered, depending on the requirements of the given analysis, using vcftools (Van der Auwera et al., 2013a, b). For all datasets, we only considered SNPs that had no missing data using vcftools option -max-missing 1.

\section{Phylogeographic reconstruction}

To perform phylogeny on our SNP dataset, a VCF file containing 218,266 SNPs was converted to phylip format using vcf2phylip (Ortiz., 2019) and used as input for IQ-TREE (Nguyen et al., 2015) to generate a maximum likelihood phylogeny with the ultrafast bootstrap option and ascertain bias correction (-st DNA -o CBS707 -m GTR+ASC -nt 8 -bb 1000) (Hoang et al., 2018). The number of parsimony informative sites was 10,680 SNPs. Trees were visualized on the iTOL website (http://itol.embl.de).

\section{Population structure analyses}

For STRUCTURE analysis, a thinned version of the VCF file was generated with vcftools 0.1.15 (-thin 500) (Danecek et al., 2011), containing 11,447 similarly-spaced SNPs, while including only L. cidristrains. Structure was run on this dataset five times for $\mathrm{K}$ values ranging from 1 to 7 , with 10,000 burn-in and 100,000 replications for each run, using admixture model, infer alpha, lambda $=1$, fpriormean $=1$, unifprioralpha 1, and alpha max 10. The structure-selector website was employed to obtain the optimal $\mathrm{K}$ values (http://lmme.qdio.ac.cn/StructureSelector/) ( $\mathrm{Li}$ and Liu, 2018) according to the Evanno method (Evanno et al., 2005). The results for each K were plotted using CLUMPAK (Kopelman et al., 2015) and visualized using a structure plot (http://omicsspeaks.com/strplot2/ ) (Ramasamy et al., 2014). In addition, we performed clustering analyses of the same samples by using SMARTPCA without outlier removal (Patterson et al., 2006). For fineSTRUCTURE analysis (Lawson et al., 2012), a VCF file that included all SNPs among L. cidri strains was phased using BEAGLE 3.0.4 (Browning and Browning, 2007). Since we lacked a $L$. cidrirecombination map, we used a constant recombination rate between consecutive SNPs based on the average recombination rate of L. kluyveri $\left(0.4 \mathrm{cM} \mathrm{kbp}^{-1}\right.$, (Brion et al., 2017)). All versus all chromosomal painting was performed with Chromopainter V2, and the output was further analyzed with fineSTRUCTURE (-x 100000 -y 100000 -z 1000). Plotting of the ancestry matrix was done using fineSTRUCTURE R scripts.

\section{Population genetics}

We estimated the pairwise of nucleotide diversity, $\pi$ and the proportion of segregant sites, $\vartheta_{\mathrm{w}}$ using the R package PopGenome (Pfeifer et al., 2014). Values of $F$ st were calculated with StAMPP 1.5.1 Weir and Cockerham's unbiased estimator to obtain $95 \%$ confidence intervals by performing 5,000 bootstraps (Pembleton et al., 2013; Weir and Cockerham, 1984). The IBD (Isolation by Distance) was performed using the twelve locations from Chile. The significance of correlations between distance matrices in the Mantel test was evaluated using 10,000 permutations. The geographic distances were calculated using latitude/longitude of all relevant sampling points using the function of GenAlEx v 6.5 (Peakall and Smouse, 2012). Population 
pairwise $F$ st values were used to build the genetic distance matrices for this test. We predict the number of generations since the most recent common ancestor of any pair of lineages using the mutation parameter $\left(\vartheta_{\mathrm{w}}=2 N,{ }_{\vartheta} \mu\right)$ as previously described (Ruderfer et al., 2006). We used the mutation rate $(\mu)$ previously reported from laboratory estimates on $S$. cerevisiae (Lynch et al., 2008).

\section{Species delimitation analysis}

We used the SNAPP software (Bryant et al., 2012) to test if species could be delimited at the molecular level using the Bayes Factors criteria implemented in BEAST v2.6 (Bouckaert et al., 2019). We evaluated four competing species models with the BFD* method (Leache et al., 2014), using as an outgroup the CBS2950 reference strain (group A, Table S2), and as the interest group we used the strains from B: Huilo-Huilo, C: Central Plateau, D: Coyhaique and E: Altos de Lircay. SNAPP analyses were only performed with a subset of individuals per genetic group for computational feasibility; the total number of SNPs in the dataset was 218,266. To change the VCF haploid to diploid we used the java code VcfFilterJdk (Lindenbaum and Redon, 2018). We used the Marginal likelihood estimation with 12 steps for the dataset to steppingstone sampling. We used default settings (e.g., Yule prior for species tree and branch length estimations; gamma distributions for ancestral theta), with five million burn-in iterations. To ensure convergence, we confirmed that our runs reached effective sample size values $>500$ after burn-in using the program Tracer v1.4 (Rambaut et al., 2018). Maximum credibility trees were generated using TreeAnnotator in BEAST v2.6, and the posterior distributions of species trees were visualized using DensiTree (Bouckaert, 2010).

\section{Phenotypic diversity among isolates}

To determine the phenotypic diversity across the L. cidriisolates, we estimated growth and biomass production in several environmental conditions that represent different yeast habitats, either in nature or in industrial settings. For this, we performed high-throughput phenotyping in 96-well microculture plates as previously described (Kessi-Perez et al., 2016). Briefly, cells were pre-cultivated in $200 \mu \mathrm{L}$ YNB medium without agitation at $20^{\circ} \mathrm{C}$ for 48 hours. For the experimental run, each well was inoculated with ten $\mu \mathrm{L}$ of pre-inoculum to an optical density (OD) of $0.03-0.1$ in $200 \mu \mathrm{L}$ of different media compositions (Table S3). Culture OD was measured at $620 \mathrm{~nm}$ every 30 minutes for 96 hours. From these data, three parameters were estimated: lag phase, growth rate ( $\mu$ max), and maximum OD using the Growth Rates software with default parameters (Hall et al., 2014).

\section{Statistical analysis}

All statistical analyses were performed using biological triplicates. The differences were considered statistically significant at $p$-values $<0.05$. The comparison of growth rate between populations and isolation locations was undertaken with a paired $t$-test. The heat map and phenotypic principal component analysis (PCA) were created using R software (Team, 2008), the "pheatmap" and "prcomp" packages stats 3.6.0, and plotted using the "ggplot2" and "ggbiplot" packages.

\section{RESULTS}

\section{High prevalence of $L$. cidri among non-Saccharomyces yeasts in natural environments}

To explore the distribution of $L$. cidri in central and southern Chile, we obtained yeast colonies from tree bark samples collected between 2017 and 2019 that had been previously identified as non-Saccharomyces (Nespolo et al., 2020b) using the internal transcribed spacer region (ITS1-5.8rRNA-ITS2). Colonies identified as L. cidri were found in 7 of the 13 sampling regions, between Altos de Lircay National Park (VII Maule Region, Chile) in the north and Coyhaique National Reserve (XI Aysén Region, Chile) in the south. Moreover, the distribution of $L$. cidri were widely-distributed in South Chile, covering regions from the Pacific coast up to the Andes Mountains (approximately 1,000 km long and $300 \mathrm{~km}$ wide) (Fig 1a, Table S4). Overall, we identified 30 L. cidristrains in Patagonia, meaning that L. cidri is the most-represented non-conventional ethanol-tolerant species in our survey. The L. cidri isolation frequency varied between 1.33 to $11.11 \%$ depending on the national park, independent of latitude (Pearson $\mathrm{r}=-0.338, p$-value $>0.05$ ) (Fig S1a, Table S4). In addition, when only non-Saccharomyces yeasts were considered, the isolation frequency values 
varied between 9.72-100\% (Fig. S1b, Table S4), indicating a high prevalence of this non-conventional yeast in Nothofagus bark samples. The samples from Chile were obtained in four different tree species, N. pumilio (representing $26.7 \%$ of the samples), $N$. dombeyi $(46.7 \%), N$. antartica $(3.3 \%)$, and A. araucana $(23.3 \%)$ (Fig. S1c). The frequency of L. cidri in Patagonia was determined by the host tree (hypergeometric test, Table S5); N. dombeyi was the most prevalent host. Additionally, colonies identified as L. cidri were obtained in a previous study from eucalyptus tree sap samples collected in the Central Plateau of Tasmania, Australia (Varela et al., 2020) (Fig. 1a). In this case, L. cidri represented $13 \%$ of the total non-Saccharomyces colonies found. Unlike Patagonia, all L. cidri isolates in Australia were obtained from E. gunnii in rich culture media without ethanol. Thus, for further analysis, we randomly selected 25 colonies from different tree sap samples. Altogether, our results demonstrate a high prevalence of $L$. cidri in Patagonia and Australia, with a wide distribution from high altitude (Andes Mountains) to low altitude regions (near the Pacific Ocean), covering an extensive range of niches and environmental conditions.

\section{Phylogenomic studies in L. cidri}

To initiate the study of the phylogeny and the genomic variations inL. cidri, we estimated the ploidy levels of the isolates. FACs analysis revealed that all L. cidri isolates were haploids (Fig. S2). Subsequently, we sequenced the complete genomes of 55 strains (30 from South America and 25 from Australia), and incorporated previously-published data for the reference strain L. cidriCBS2950 (isolated from cider in France) and the L. fermentatistrain CBS707, which we used as an outgroup. On average, across the 30 South American genomes, we obtained 2,670 SNPs per strain relative to the reference genome (SNPs were found on average every $\sim 3.8 \mathrm{~kb}$ between two strains). On the other hand, across the 25 Australian genomes, we obtained on average 36 SNPs per strain relative to the reference genome (SNPs were found on average every $\sim 282 \mathrm{~kb}$ ), indicating apparent differences compared to the South American group of strains. In parallel, we found different numbers of insertions and deletions depending on the strain relative to the reference genome, ranging from 79 in the Australian strains to 124 in the South American strains (the Bioinformatic Summary statistics are shown in Table S6). Interestingly, the high number of INDELs are unique to the reference strain, rather than a general trend between any two strains (Table S6).

The phylogeographic result with maximum-likelihood phylogeny revealed a topology with two well-supported main clades separating South American and Australian strains (Fig. 1b). Australian strains clustered into a single clade (hereafter referred to as Aus), together with the European reference strain L. cidri CBS2950. This clustering of Australian and European strains, together with the low number of polymorphisms found between them (Table S7), suggest a recent migration event between both regions. In contrast, the South American strains were separated in a more complex clade distribution, with substantial differences in branch lengths, as well as different subclades with phylogeographic structures (Fig. 1b). The South American clade (hereafter referred to as SoAm) harbored 15,706 unique SNPs compared to the reference strain (Table S7). Interestingly, the two isolates from Altos de Lircay National Park (AL) (the northernmost locality) (Fig. 1a) cluster together, and harbor the greatest genetic divergence within the SoAm group (Fig 1b). Overall, these results suggest a broader genetic diversity in SoAm compared to Aus lineages, where the AL branch showed the highest genetic divergence in the latitudinal gradient (Fig. 1b).

\section{Population structure analyses reveal two main genetic groups inL. cidri.}

To explore the connection between strains and localities, we performed an analysis of the distribution of the genetic variants found in the $55 \mathrm{~L}$. cidri strains (Fig. 2a and b). The principal component analysis (PCA) showed a clear separation of the strains depending on their geographical origin, where according to the first two components, PC1 $(11.2 \%)$ and PC2 (8.98\%), the Aus group is completely separated from the other set of strains (Fig. 2a), illustrating again the genetic differentiation between Aus and SoAm L. cidri . Interestingly, SoAm exhibited a separation into two additional groups, one corresponding to AL (most divergent clade) located in the upper part of the PCA plot and the other in the lower part corresponding to the remaining SoAm strains (Fig. 2a). A second PCA considering just the latter group, clearly revealed that the strains distributed based on their geographic origin of isolation, including latitude and longitude. According to the first two principal components, PC1 $(7.84 \%)$ and PC2 $(6.62 \%)$, those strains collected near to the 
Pacific Ocean (Valdivian Coastal Reserve and Chiloé National Park) separated from those isolates obtained in mountainous regions (color chart, Fig. 2b).

To determine the population genetic structure of L. cidri, we performed several complementary approaches, including STRUCTURE, ADMIXTURE, and fineSTRUCTURE clustering (Fig. 2c and d). The three analyses revealed a high degree of differentiation between strains isolated from South America and Australia. STRUCTURE and ADMIXTURE analyses indicated an optimum $\mathrm{K}=2$ groups $\left(\Delta \mathrm{K}_{2}=301\right.$ for STRUCTURE, Fig. 2c, Table S8), showing the presence of two genetic groups, SoAm and Aus. Further analysis using the fineSTRUCTURE Co-ancestry matrix indicated a clear separation between the SoAm and Aus isolates (Fig. 2d), confirming the presence of two large populations. Additionally, we identified a series of subgroups within the SoAm clade, suggesting sub evolutionary units in central and southern Chile confirming the great differentiation and divergence of the group of isolates obtained from AL. To corroborate the results obtained, we calculated the genetic differentiation $\left(F_{\mathrm{ST}}\right)$ between each of the localities from which L. cidri isolates were obtained (Fig. 2e, Table S9). In this case, we found low to high $F$ st values ranging from 0.04 ( $p$-value $<0.001)$ between Villarrica National Park and the Huilo-Huilo Biological Reserve, up to 0.99 ( $p$-value $<0.001)$ between Altos de Lircay National Park (AL) and Central Plateau of Tasmania (CP), Australia (Fig. 2e). Although the STRUCTURE and ADMIXTURE analyses did not suggest AL as a third lineage, we found the highest $F$ sT values between AL and the other localities from South America, suggesting that this could represent a third population in our study (Fig. 2e, Table S9). Intermediate and low $F$ ST values were found between closer localities in southern Chile (Fig. 2e, Table S9). Under this scenario, with IBD we found a moderately significant correlation $\left(\mathrm{R}^{2}=0.39, p\right.$-value $\left.=0.05\right)($ Fig. $2 \mathrm{f})$ between genetic differentiation and geographic distance in the localities of southern Chile, suggesting that the genetic differences found in Patagonian L. cidri could result from the geographical distribution (distance in kilometers).

SoAm isolates exhibited higher genetic diversity compared to those from Australia. In this case, we calculated nucleotide diversity $(\pi)$ (Fig. S3a, Table S10). In general, we observed a higher nucleotide diversity in the SoAm population, most likely due to the number of different locations from which the L. cidri strains were isolated (Fig. 3b). When analyzing the diversity at each locality, higher $\pi$ values were observed in sampling sites from southern Chile (e.g., Coyhaique National Reserve) compared to central Chile (e.g., Altos de Lircay) or Australia, which exhibited the lowest $\pi$ values (Fig. S3b), despite being the location with the highest number of isolates $(\mathrm{n}=25)$. To confirm the results obtained, we compared the nucleotide diversity of the Huilo-Huilo Biological Reserve (locality with the highest number of isolates in South America, $\mathrm{n}=10$ ) with the same number of randomly-selected isolates from the Australian population. As in the previous case, we observed a great diversity in the strains of the Huilo-Huilo population compared to the Australian strains, confirming the greater genetic diversity found in Patagonia. Furthermore, the low number of SNPs between the French reference strain and the Australian population, also suggest a likely low genetic diversity in Australia. The low nucleotide diversity found in the Australian population could be due to a short divergence time, suggesting a recent introduction of the species in Australia or Europe (Fig. S3b, Table S10).

\section{Pleistocene dated divergence between the main evolutionary units in $L$. cidri}

Given the genetic divergence of the AL clade and considering the distribution of SNPs according to the PCA, the clustering in the co-ancestry matrix in fineSTRUCTURE and the high $F$ sT values compared to the rest of the SoAm populations, we evaluated the possibility that the group of isolates from AL could represent a different lineage or evolutionary unit in the species. For this, we performed a species delimitation analyses according to the different models generated, and hypothesized the presence of 1 to 4 genetically-different linages or groups utilizing CBS2950, Aus, AL, HH and CY as representatives of the different lineages (Fig. 3a). The Bayes factor species delimitation (SNAPP) analysis supported the scenario where AL represents a different evolutionary unit in the species (model 4, Fig 3a), exhibiting the highest Bayes factor (-180457.18) (Table S2) and a high Bayesian support (IB = 1, Fig 3a). In addition, this analysis also predicts the presence of 4 different groups separating $\mathrm{HH}$ and $\mathrm{CY}$ as a different unit (Table S2); however, the Bayesian support 
in the species tree was low and therefore these could not be considered as different evolutionary unit (IB $=$ 0.75, Fig 3a). Altogether, this suggests the presence of 3 different evolutionary units in L. cidri : Aus, AL and SoAm.

Considering the results obtained, we use the population genomic data to estimate the divergence time since the most recent common ancestor between lineages. Following the same strategy as previously used for L. kluyveri and S. cerevisiae (Friedrich et al., 2015; Ruderfer et al., 2006) we predicted the number of generations that have passed since the divergence of any two groups. Our data lead to an estimation of $23.9 \times 10^{6}$ generations since the most recent common ancestor in L. cidri. In the Australian lineage, we obtained an estimation of $1.5 \times 10^{5}$ generation since the most recent common ancestor of the Australian strains and the reference CBS2950 strain. In contrast to this, when we analyzed the number of generations of the AL most recent common ancestor, we obtain $23 \times 10^{6}$ generations. Considering that cell division of yeast in the wild ranges from 1 to 8 generations per day (Fay and Benavides, 2005), the divergence time of the Australia and South America lineage correspond to approximately 64-8 KYA (Fig 3b), dating back to the upper Pleistocene. On the other hand, the divergence of the Australian strains and the CBS2950 strain is very recent and corresponds to approximately 405-51 YA (Fig 3b). Finally, the coalescence time of the AL lineage would correspond to approximately 62-7.8 KYA.

\section{Phenotypic diversity across $L$. cidri populations}

To estimate the impact of genetic diversity upon phenotypic diversity, we assessed the phenotypic diversity of $L$. cidri in the complete set of 56 isolates. For this, we performed microcultures and estimated growth rates ( $\mu$ max, corresponding to the maximum specific growth rate) from curves obtained under 12 conditions comprising different carbon sources, stresses, and environmental parameters. A clustered heat map of the phenotypic correlations between strains showed a separation of the isolates according to their geographic origin, either from SoAm or from Aus, except for three Australian isolates that clustered together with strains from Patagonia (Fig. 4a, Table S11). In this sense, hierarchical clustering of the phenotypic data distributed the strains across four main clades (Fig. 4a). Cluster A contained two isolates (one from SoAm and one from Aus), showing the lowest growth rates for most conditions (Fig. 4a). The different SoAm isolates distributed in Clusters B and C. Cluster B showed the greatest growth rates compared to the other three clusters, while Cluster $\mathrm{C}$ showed intermediate values and exhibited low growth rates in fructose and ethanol. Interestingly, all isolates in Cluster $\mathrm{C}$ belong to localities close to the Pacific Ocean (low altitude, Valdivian Coastal Reserve, and Chiloé National Park) (Fig. 4a). Most strains from Australia distributed in Cluster D $(n=20)$. However, three Australian strains grouped in cluster B, likely because of their greater growth rates using maltose and fructose as carbon sources. The main difference between clusters is the ability of the strains to grow in ethanol-containing media. In this case, we observed significant differences when we compared the growth rate between all clusters $(p$-value $<0.001$, t-test). For example, in Clusters B and D we found isolates with the highest growth rates under $6 \%$ ethanol. Cluster B contains SoAm isolates from high altitude localities together with strain CBS2950 and three strains of the Aus lineage. On the other hand, Cluster D consists entirely of Aus lineage isolates.

We observed a clear separation between the SoAm and Aus populations (Fig. S4) using PCA, allowing us to further dissect the phenotypic data (Fig. S4). When analyzing the distribution of each isolate, we also observed a separation based on locality (Fig. S4b). Nevertheless, the SoAm populations exhibited the greatest growth rates across the different conditions compared to the Aus isolates $(p$-value $<0.001$, $\mathrm{t}$ test) (Fig. S5a). The SoAm populations exhibited phenotypic differences based on longitude. We found two phenotypic groups, termed high and low altitude locations (HA and LA, respectively), depending on whether they were collected near the Andes or the Pacific Coast, respectively (Fig. 4a). In general, strains isolated from HA locations show greater growth rates than those isolated from LA locations $(p$-value $<$ 0.001 , t-test) (Fig. S4b). Interestingly, LA strains showed a higher growth rate than HA only in $2 \%$ maltose ( $p$-value $<0.05$, t-test) (Fig. S5c). The longitude comparison showed significant differences for 8 of the 12 conditions evaluated ( $p$-value $<0.05$, t-test) (Fig. S5c), with the most notable differences ( $p$-value $<$ 0.001 , t-test) in ethanol $(6$ and $8 \% \mathrm{v} / \mathrm{v})$, glucose $(20 \% \mathrm{w} / \mathrm{v})$, sorbitol $(20 \% \mathrm{w} / \mathrm{v})$ and $\mathrm{NaCl}(1.25 \mathrm{mM})($ Fig. 
S5c). Overall, the phenotypic data demonstrate that the ecological niche is determinant in the differences observed, highlighting the different conditions in which $L$. cidrican grow from localities near to the Pacific Coast up to high altitudes in the Andes.

\section{DISCUSSION}

Large-scale population genomics studies performed onSaccharomyces spp. allowed us to understand yeast dynamics in nature and their association with anthropogenic environments (Peter and Schacherer, 2016). In this sense, the analysis of complete genomes and the use of molecular markers aided the understanding of the natural genetic diversity in Saccharomyces populations and highlights how they adapt to the environments which they inhabit (Almeida et al., 2015; Almeida et al., 2014; Bendixsen et al., 2021; Parts et al., 2021; Peter and Schacherer, 2016). In the last decade, advances in sequencing technologies have made it possible to extrapolate this type of study to non-model species that have long been overlooked (Bansal and Boucher, 2019; Dujon and Louis, 2017). L. cidri, a non-model species, is an attractive model to study since it's a Crabtree-positive yeast located phylogenetically before the whole-genome duplication (Porter et al., 2019b; Vakirlis et al., 2016), and which exhibits substantial biotechnological potential for fermentation (Villarreal et al., 2021). In contrast to Saccharomyces spp., which are mostly diploid in nature (Almeida et al., 2014; Nespolo et al., 2020b; Peter et al., 2018), L. cidri isolates are haploids, which might be indicative of a different reproductive cycle. It has been reported that even with identical genomes, ploidy itself is known to have different effects on yeasts. Therefore, understanding how ploidy affects the ecology and evolution of organisms has long been a topic of interest (Gerstein et al., 2011; Gerstein and Otto, 2009). Haploid yeasts have a competitive advantage over diploid yeasts. For example, one of the main differences between the two ploidy levels is cell size, where differences in volume have been shown to directly affect relative fitness in some environments. Under nutrient stress, for example, where a limited concentration of nutrients diffuses across the cell membrane, haploid organisms would have a greater advantage, likely favoring their survival under extreme environmental conditions (Gerstein et al., 2011).

Our results demonstrate that $L$. cidri is widely-distributed in Patagonia. In fact, L. cidri is found between latitudes $35{ }^{\circ} \mathrm{S}$ and $45{ }^{\circ} \mathrm{S}$ in Australia and Patagonia, which in general are considered non-Mediterranean (cold regions). However, L. cidri was not found in extreme southern regions such as Tierra del Fuego (54 $\left.{ }^{\circ} \mathrm{S}\right)$, probably due to southern Patagonia's extreme cold climatic conditions, where the temperature is below freezing for a large fraction of the year (Ponce JF and M., 2014). Samples obtained in South America were collected from tree species belonging to the genera Nothofagus and Araucaria in National Parks from Chile, covering approximately 1,000 km of territory. Then, the biogeographical history of the South American population of L. cidri correlates well with the history and distribution of the Nothofagus forest, comparable to reports for other species isolated in Patagonia (Saccharomyces and non-Saccharomyces ) (Nespolo et al., 2020b). Our results agree with previous findings, where it has been demonstrated that L. cidri exhibits significant host preference, being more frequently isolated from $N$. dombeyi in Patagonia (Nespolo et al., 2020b; Villarreal et al., 2021). In this way, this study, together with previous studies in Saccharomyces yeasts from forests ecosystems (Cadez et al., 2021; Langdon et al., 2020; Libkind et al., 2011; Nespolo et al., 2020b) demonstrate the impact of the Nothofagus biome (Woodward et al., 2004) across the southern hemisphere on the current distribution of the Lachancea genus throughout Patagonia.

The phylogenomic analysis of wild $L$. cidri strains demonstrates the remarkable genetic diversity present in South America. Unlike Australia, where isolates were collected from a smaller territory and showed relatively low genetic variation (Varela et al., 2020), in South America, a broad geographic distribution with varied seasonal and spatial variation generated an enormous genetic differentiation and nucleotide diversity. Therefore, our population structure analysis, developed with different strategies, generated a consistent phylogenetic picture: two populations depending on geographic origin (SoAm and Aus), with the Australian isolates forming a tight cluster with the reference strain from France (CBS2950). The Australian population shows a low genetic diversity $(\pi=0,00005)$, indicating a recent common ancestor. Despite the large geographic distance between Australian isolates and the French reference strain, we found a low genetic differentiation between both, which would suggest a recent exchange between Australia and Europe, likely coalescing between 405 to 
51 years ago. In contrast, the variability found within the South American population is in accordance with the different localities from which the isolates were obtained. The different environmental conditions and the extensive distribution of the Nothofagus forest in Patagonia likely facilitated the presence of a unique genetic diversity (Cadez et al., 2019; Cubillos et al., 2019; Nespolo et al., 2020b; Villarreal et al., 2021), which is reflected in our study. In the same way, the phenotypic data corroborates the large genetic diversity observed in Patagonia. Although it has been reported that genetic diversity is not always a reflection of diversity at the physiological level (Banilas et al., 2016; Pfliegler et al., 2014), we were able to demonstrate how a greater diversity at the genetic level is determinant when performing phenotypic analyses under natural and stressful conditions.

The divergence between Australian and South America strains is interesting and deserves attention. The split could have originated in the Cretaceous-Early Tertiary interchange when Nothofagusoriginated, and continents were separated (Hill, 1992). The absence of fossil records for yeasts complicates the interpretation, but the geographic origin of our samples, the high association with native forests with a well-documented phylogeographic history (e.g., (Acosta et al., 2014; Hinojosa et al., 2016), and the genetic differences found in L. cidri from South America permit to delineate some hypotheses. The last glacial maximum (LGM) during the Late Pleistocene ( $\sim 35,000$ years ago, see Davies et al. 2020)(Davies et al., 2020) resulted in an ice cover that expanded through the south of South America from latitude $53^{\circ} \mathrm{S}$ to $38^{\circ} \mathrm{S}$, leaving only few areas free of ice, such as Altos de Lircay (Hewitt, 2000; Hinojosa, 1997). Thus, most areas including Coyhaique were covered by the ice, and present-day plants and animals are young populations that colonized the area either from Argentina or from coastal refuges, during the last ${ }^{10,000}$ years. This large isolation barrier would explain the divergence observed between the South American L. cidri populations, unlike the French and Australian strains that likely migrated because of human movements.

In summary, our results demonstrate the presence of two genetically-different populations in L. cidri . In the same way, it is possible to suggest that the geographic location and the ecological niche (host) where each isolate was found are essential factors in determining the genetic differentiation and nucleotide diversity observed in this species. Our results show a high phylogeographic structure among the localities of South America. The high diversity, species delimitation method and genetic differences between Altos de Lircay populations and southern populations in Patagonia suggest that the former represents a different evolutionary unit. This is a striking result, since the unique conditions of Patagonia during the Late Pleistocene could have contributed to the differentiation of L. cidri populations in South America. Furthermore, we propose that there was a recent exchange between Australia and France due to the low genetic differentiation between strains from both regions. In conclusion, this work provides a valuable insight into the genetic and phenotypic diversity of L. cidri, contributing to a better understanding of phylogeography, population structure, ecology, and divergence time of this underexplored yeast species, with remarkable biotechnological potential.

\section{ACKNOWLEDGMENTS}

FC acknowledges the Comisión Nacional de Investigación Científica y Tecnológica CONICYT FONDECYT [1180161] and ANID - Programa Iniciativa Científica Milenio - ICN17_022. PV is supported by ANID FONDECYT POSTDOCTORADO [grant 3200575]. RN is supported by FIC 'Transferencia Levaduras Nativas para Cerveza Artesanal' and FONDECYT grant [1180917]. FC, RN, PV, TP, SO, and GF were funded by PROGRAMA DE COOPERACIÓN CIENTÍFICA ECOS-CONICYT ECOS180003. We thank Dr. Vladimir Jiranek from the University of Adelaide and the AWRI Culture Collection for access to L. cidri isolates, Michael Handford (Universidad de Chile) for language support and Fundación Huilo Huilo for the assistance during the fieldwork. We also acknowledge Fundación Ciencia \& Vida for providing infrastructure, laboratory space and equipment for experiments.

\section{Author Contributions}

Conceptualization: P.V., C.V., F.A.C. Formal analysis:P.V. Investigation: P.V., C.A.V., S.O., N.A., T.P., J.F.Q-G, C.V. Writing - original draft: P.V., F.A.C. Writing - review \& editing: P.V., R.F.N., C.V., G.F., J.F.Q-G, F.A.C. 


\section{Conflicts of interest}

The authors declare that there are no conflicts of interest.

\section{Ethical statement}

This article does not contain any studies with human nor animal subjects performed by any of the authors.

\section{References}

Acosta, M.C., Mathiasen, P., and Premoli, A.C. (2014). Retracing the evolutionary history of Nothofagus in its geo-climatic context: new developments in the emerging field of phylogeology. Geobiology 12 , 497-510.

Agier, N., Delmas, S., Zhang, Q., Fleiss, A., Jaszczyszyn, Y., van Dijk, E., Thermes, C., Weigt, M., CosentinoLagomarsino, M., and Fischer, G. (2018). The evolution of the temporal program of genome replication. Nat Commun $9,2199$.

Almeida, P., Barbosa, R., Zalar, P., Imanishi, Y., Shimizu, K., Turchetti, B., Legras, J.L., Serra, M., Dequin, S., Couloux, A., et al. (2015). A population genomics insight into the Mediterranean origins of wine yeast domestication. Mol Ecol 24, 5412-5427.

Almeida, P., Goncalves, C., Teixeira, S., Libkind, D., Bontrager, M., Masneuf-Pomarede, I., Albertin, W., Durrens, P., Sherman, D.J., Marullo, P., et al. (2014). A Gondwanan imprint on global diversity and domestication of wine and cider yeast Saccharomyces uvarum. Nat Commun5 , 4044.

Andrews, S. (2010). FastQC: A Quality Control Tool for High Throughput Sequence Data. Available online at:http://wwwbioinformaticsbabrahamacuk/projects/fastqc(accessed December 5, 2019).

Banilas, G., Sgouros, G., and Nisiotou, A. (2016). Development of microsatellite markers for Lachancea thermotolerans typing and population structure of wine-associated isolates. Microbiol Res193 , 1-10.

Bansal, V., and Boucher, C. (2019). Sequencing Technologies and Analyses: Where Have We Been and Where Are We Going? iScience $18,37-41$.

Bellut, K., Krogerus, K., and Arendt, E.K. (2020). Lachancea fermentati Strains Isolated From Kombucha: Fundamental Insights, and Practical Application in Low Alcohol Beer Brewing. Front Microbiol 11, 764.

Bendixsen, D.P., Gettle, N., Gilchrist, C., Zhang, Z., and Stelkens, R. (2021). Genomic Evidence of an Ancient East Asian Divergence Event in Wild Saccharomyces cerevisiae. Genome Biol Evol 13 .

Bouckaert, R., Vaughan, T.G., Barido-Sottani, J., Duchene, S., Fourment, M., Gavryushkina, A., Heled, J., Jones, G., Kuhnert, D., De Maio, N., et al. (2019). BEAST 2.5: An advanced software platform for Bayesian evolutionary analysis. PLoS Comput Biol 15 , e1006650.

Bouckaert, R.R. (2010). DensiTree: making sense of sets of phylogenetic trees. Bioinformatics 26 , 1372-1373.

Brickwedde, A., Brouwers, N., van den Broek, M., Gallego Murillo, J.S., Fraiture, J.L., Pronk, J.T., and Daran, J.G. (2018). Structural, Physiological and Regulatory Analysis of Maltose Transporter Genes in Saccharomyces eubayanus CBS 12357(T). Front Microbiol $9,1786$.

Brion, C., Legrand, S., Peter, J., Caradec, C., Pflieger, D., Hou, J., Friedrich, A., Llorente, B., and Schacherer, J. (2017). Variation of the meiotic recombination landscape and properties over a broad evolutionary distance in yeasts. PLoS Genet 13 , e1006917.

Browning, S.R., and Browning, B.L. (2007). Rapid and accurate haplotype phasing and missing-data inference for whole-genome association studies by use of localized haplotype clustering. Am J Hum Genet 81 , 1084-1097.

Bryant, D., Bouckaert, R., Felsenstein, J., Rosenberg, N.A., and RoyChoudhury, A. (2012). Inferring species trees directly from biallelic genetic markers: bypassing gene trees in a full coalescent analysis. Mol Biol Evol $29,1917-1932$. 
Cadez, N., Bellora, N., Ulloa, R., Hittinger, C.T., and Libkind, D. (2019). Genomic content of a novel yeast species Hanseniaspora gamundiae sp. nov. from fungal stromata (Cyttaria) associated with a unique fermented beverage in Andean Patagonia, Argentina. PLoS One 14, e0210792.

Cadez, N., Bellora, N., Ulloa, R., Tome, M., Petkovic, H., Groenewald, M., Hittinger, C.T., and Libkind, D. (2021). Hanseniaspora smithiae sp. nov., a Novel Apiculate Yeast Species From Patagonian Forests That Lacks the Typical Genomic Domestication Signatures for Fermentative Environments. Front Microbiol 12 , 679894 .

Chen, J., Shen, W., Xu, H., Li, Y., and Luo, T. (2019). The Composition of Nitrogen-Fixing Microorganisms Correlates With Soil Nitrogen Content During Reforestation: A Comparison Between Legume and Nonlegume Plantations. Front Microbiol 10, 508.

Chen, S., Zhou, Y., Chen, Y., and Gu, J. (2018). fastp: an ultra-fast all-in-one FASTQ preprocessor. Bioinformatics 34 , i884-i890.

Cubillos, F.A., Gibson, B., Grijalva-Vallejos, N., Krogerus, K., and Nikulin, J. (2019). Bioprospecting for brewers: Exploiting natural diversity for naturally diverse beers. Yeast 36 , 383-398.

Danecek, P., Auton, A., Abecasis, G., Albers, C.A., Banks, E., DePristo, M.A., Handsaker, R.E., Lunter, G., Marth, G.T., Sherry, S.T., et al. (2011). The variant call format and VCFtools. Bioinformatics (Oxford, England) 27, 2156-2158.

Dashko, S., Zhou, N., Compagno, C., and Piskur, J. (2014). Why, when, and how did yeast evolve alcoholic fermentation? FEMS Yeast Res14, 826-832.

Davies, B.J., Darvill, C.M., Lovell, H., Bendle, J.M., Dowdeswell, J.A., Fabel, D., Garcia, J.L., Geiger, A., Glasser, N.F., Gheorghiu, D.M., et al. (2020). The evolution of the Patagonian Ice Sheet from 35 ka to the present day (PATICE). Earth-Sci Rev 204.

DePristo, M.A., Banks, E., Poplin, R., Garimella, K.V., Maguire, J.R., Hartl, C., Philippakis, A.A., del Angel, G., Rivas, M.A., Hanna, M., et al. (2011). A framework for variation discovery and genotyping using next-generation DNA sequencing data. Nat Genet43 , 491-498.

Dujon, B.A., and Louis, E.J. (2017). Genome Diversity and Evolution in the Budding Yeasts (Saccharomycotina). Genetics $206,717-750$.

Esteve-Zarzoso, B., Peris-Toran, M.J., Garcia-Maiquez, E., Uruburu, F., and Querol, A. (2001). Yeast population dynamics during the fermentation and biological aging of sherry wines. Appl Environ Microbiol 67 , 2056-2061.

Evanno, G., Regnaut, S., and Goudet, J. (2005). Detecting the number of clusters of individuals using the software STRUCTURE: a simulation study. Mol Ecol 14, 2611-2620.

Fay, J.C., and Benavides, J.A. (2005). Evidence for domesticated and wild populations of Saccharomyces cerevisiae. PLoS Genet 1, 66-71.

Ford, C.B., Funt, J.M., Abbey, D., Issi, L., Guiducci, C., Martinez, D.A., Delorey, T., Li, B.Y., White, T.C., Cuomo, C., et al.(2015). The evolution of drug resistance in clinical isolates of Candida albicans. Elife 4 , $\mathrm{e} 00662$.

Fournier, T., Gounot, J.S., Freel, K., Cruaud, C., Lemainque, A., Aury, J.M., Wincker, P., Schacherer, J., and Friedrich, A. (2017). High-Quality de Novo Genome Assembly of the Dekkera bruxellensis Yeast Using Nanopore MinION Sequencing. G3 (Bethesda) 7 , 3243-3250.

Friedrich, A., Jung, P., Reisser, C., Fischer, G., and Schacherer, J. (2015). Population genomics reveals chromosome-scale heterogeneous evolution in a protoploid yeast. Mol Biol Evol 32 , 184-192. 
Friedrich, A., Jung, P.P., Hou, J., Neuveglise, C., and Schacherer, J. (2012). Comparative mitochondrial genomics within and among yeast species of the Lachancea genus. PLoS One 7, e47834.

Fujita, S.I., Senda, Y., Nakaguchi, S., and Hashimoto, T. (2001). Multiplex PCR using internal transcribed spacer 1 and 2 regions for rapid detection and identification of yeast strains. J Clin Microbiol39, 3617-3622.

Gabaldon, T., and Fairhead, C. (2019). Genomes shed light on the secret life of Candida glabrata: not so asexual, not so commensal. Curr Genet65 , 93-98.

Gallone, B., Steensels, J., Prahl, T., Soriaga, L., Saels, V., Herrera-Malaver, B., Merlevede, A., Roncoroni, M., Voordeckers, K., Miraglia, L., et al. (2016). Domestication and Divergence of Saccharomyces cerevisiae Beer Yeasts. Cell 166 , 1397-1410 e1316.

García-Alcalde, F., Okonechnikov, K., Carbonell, J., Cruz, L.M., Götz, S., Tarazona, S., Dopazo, J., Meyer, T.F., and Conesa, A. (2012). Qualimap: evaluating next-generation sequencing alignment data. Bioinformatics 28, 2678-2679.

Gerstein, A.C., Cleathero, L.A., Mandegar, M.A., and Otto, S.P. (2011). Haploids adapt faster than diploids across a range of environments. J Evol Biol 24, 531-540.

Gerstein, A.C., and Otto, S.P. (2009). Ploidy and the causes of genomic evolution. J Hered 100, 571-581.

Goncalves, M., Pontes, A., Almeida, P., Barbosa, R., Serra, M., Libkind, D., Hutzler, M., Goncalves, P., and Sampaio, J.P. (2016). Distinct Domestication Trajectories in Top-Fermenting Beer Yeasts and Wine Yeasts. Curr Biol 26 , 2750-2761.

Gonzalez, S.S., Barrio, E., and Querol, A. (2007). Molecular identification and characterization of wine yeasts isolated from Tenerife (Canary Island, Spain). J Appl Microbiol 102, 1018-1025.

Gounot, J.S., Neuveglise, C., Freel, K.C., Devillers, H., Piskur, J., Friedrich, A., and Schacherer, J. (2020). High Complexity and Degree of Genetic Variation in Brettanomyces bruxellensis Population. Genome Biol Evol $12,795-807$.

Guaragnella, N., Chiara, M., Capece, A., Romano, P., Pietrafesa, R., Siesto, G., Manzari, C., and Pesole, G. (2019). Genome Sequencing and Comparative Analysis of Three Hanseniaspora uvarum Indigenous Wine Strains Reveal Remarkable Biotechnological Potential. Front Microbiol10 , 3133.

Hagman, A., Sall, T., and Piskur, J. (2014). Analysis of the yeast short-term Crabtree effect and its origin. FEBS J 281, 4805-4814.

Hall, B.G., Acar, H., Nandipati, A., and Barlow, M. (2014). Growth rates made easy. Mol Biol Evol 31 , 232-238.

Hewitt, G. (2000). The genetic legacy of the Quaternary ice ages. Nature405 , 907-913.

Hill, R.S. (1992). Nothofagus: Evolution from a southern perspective. Trends Ecol Evol 7 , 190-194.

Hinojosa, L.F., Gaxiola, A., Perez, M.F., Carvajal, F., Campano, M.F., Quattrocchio, M., Nishida, H., Uemura, K., Yabe, A., Bustamante, R., et al. (2016). Non-congruent fossil and phylogenetic evidence on the evolution of climatic niche in the Gondwana genus Nothofagus. Journal of Biogeography 43, 555-567.

Hinojosa, L.F.V., C. (1997). Historia de los bosques del sur de Sudamerica, I: antecedentes paleobotanicos, geologicos y climaticos del Terciario del cono sur de America. Rev Chil Hist Nat 70 , 225-239.

Hirakawa, M.P., Martinez, D.A., Sakthikumar, S., Anderson, M.Z., Berlin, A., Gujja, S., Zeng, Q., Zisson, E., Wang, J.M., Greenberg, J.M., et al. (2015). Genetic and phenotypic intra-species variation in Candida albicans. Genome Res $25,413-425$.

Hoang, D.T., Chernomor, O., von Haeseler, A., Minh, B.Q., and Vinh, L.S. (2018). UFBoot2: Improving the Ultrafast Bootstrap Approximation. Mol Biol Evol 35 , 518-522. 
Hranilovic, A., Bely, M., Masneuf-Pomarede, I., Jiranek, V., and Albertin, W. (2017). The evolution of Lachancea thermotolerans is driven by geographical determination, anthropisation and flux between different ecosystems. PLoS One 12, e0184652.

Hranilovic, A., Gambetta, J.M., Schmidtke, L., Boss, P.K., Grbin, P.R., Masneuf-Pomarede, I., Bely, M., Albertin, W., and Jiranek, V. (2018). Oenological traits of Lachancea thermotolerans show signs of domestication and allopatric differentiation. Sci Rep 8, 14812.

Kessi-Perez, E.I., Araos, S., Garcia, V., Salinas, F., Abarca, V., Larrondo, L.F., Martinez, C., and Cubillos, F.A. (2016). RIM15 antagonistic pleiotropy is responsible for differences in fermentation and stress response kinetics in budding yeast. FEMS Yeast Res 16 .

Kodama, K., and Kyono, T. (1974). Ascosporogenous yeasts isolated from tree exudates in Japan. v. 52 .

Kopelman, N.M., Mayzel, J., Jakobsson, M., Rosenberg, N.A., and Mayrose, I. (2015). Clumpak: a program for identifying clustering modes and packaging population structure inferences across K. Mol Ecol Resour 15 , 1179-1191.

Kurtzman, C. (2003). Phylogenetic circumscription of , and other members of the Saccharomycetaceae, and the proposal of the new genera, , , and. FEMS Yeast Research 4, 233-245.

Lachance, M.-A., and Kurtzman, C.P. (2011). Lachancea. In The Yeasts, pp. 511-519.

Langdon, Q.K., Peris, D., Eizaguirre, J.I., Opulente, D.A., Buh, K.V., Sylvester, K., Jarzyna, M., Rodriguez, M.E., Lopes, C.A., Libkind, D., et al. (2020). Postglacial migration shaped the genomic diversity and global distribution of the wild ancestor of lager-brewing hybrids. PLoS Genet 16 , e1008680.

Lawson, D.J., Hellenthal, G., Myers, S., and Falush, D. (2012). Inference of population structure using dense haplotype data. PLoS Genet8, e1002453.

Leache, A.D., Fujita, M.K., Minin, V.N., and Bouckaert, R.R. (2014). Species delimitation using genomewide SNP data. Syst Biol 63, 534-542.

Lee, C.F., Yao, C.H., Liu, Y.R., Hsieh, C.W., and Young, S.S. (2009). Lachancea dasiensis sp. nov., an ascosporogenous yeast isolated from soil and leaves in Taiwan. Int J Syst Evol Microbiol 59 , 1818-1822.

Li, H. (2013). Aligning sequence reads, clone sequences and assembly contigs with BWA-MEM. 1303 .

Li, H., Handsaker, B., Wysoker, A., Fennell, T., Ruan, J., Homer, N., Marth, G., Abecasis, G., and Durbin, R. (2009). The Sequence Alignment/Map format and SAMtools. Bioinformatics 25 , 2078-2079.

Li, Y.L., and Liu, J.X. (2018). StructureSelector: A web-based software to select and visualize the optimal number of clusters using multiple methods. Mol Ecol Resour 18 , 176-177.

Libkind, D., Hittinger, C.T., Valerio, E., Goncalves, C., Dover, J., Johnston, M., Goncalves, P., and Sampaio, J.P. (2011). Microbe domestication and the identification of the wild genetic stock of lager-brewing yeast. Proc Natl Acad Sci U S A 108 , 14539-14544.

Lindenbaum, P., and Redon, R. (2018). bioalcidae, samjs and vcffilterjs: object-oriented formatters and filters for bioinformatics files. Bioinformatics 34, 1224-1225.

Liti, G., Carter, D.M., Moses, A.M., Warringer, J., Parts, L., James, S.A., Davey, R.P., Roberts, I.N., Burt, A., Koufopanou, V., et al. (2009). Population genomics of domestic and wild yeasts. Nature458, 337-341.

Liu, W., Luo, Z., Wang, Y., Pham, N.T., Tuck, L., Pérez-Pi, I., Liu, L., Shen, Y., French, C., Auer, M., et al. (2018). Rapid pathway prototyping and engineering using in vitro and in vivo synthetic genome SCRaMbLEin methods. Nature Communications $9,1936$.

Lynch, M., Sung, W., Morris, K., Coffey, N., Landry, C.R., Dopman, E.B., Dickinson, W.J., Okamoto, K., Kulkarni, S., Hartl, D.L., et al.(2008). A genome-wide view of the spectrum of spontaneous mutations in 
yeast. Proc Natl Acad Sci U S A 105 , 9272-9277.

Magalhães, K.T., de Melo Pereira, G.V., Campos, C.R., Dragone, G., and Schwan, R.F. (2011). Brazilian kefir: structure, microbial communities and chemical composition. Braz J Microbiol 42 , 693-702.

Marsh, A.J., O'Sullivan, O., Hill, C., Ross, R.P., and Cotter, P.D. (2014). Sequence-based analysis of the bacterial and fungal compositions of multiple kombucha (tea fungus) samples. Food Microbiol 38 , $171-178$.

Mesquita, V.A., Magalhães-Guedes, K., Silva, C., and Schwan, R. (2013). The molecular phylogenetic diversity of bacteria and fungi associated with the cerrado soil from different regions of Minas Gerais, Brazil. Int J Microbiol Res 4, 119-131.

Mirza, B.S., Potisap, C., Nusslein, K., Bohannan, B.J., and Rodrigues, J.L. (2014). Response of free-living nitrogen-fixing microorganisms to land use change in the Amazon rainforest. Appl Environ Microbiol80 , 281-288.

Morata, A., Loira, I., Tesfaye, W., Bañuelos, M., González, C., and Suárez Lepe, J. (2018). Lachancea thermotolerans Applications in Wine Technology. Fermentation 4.

Nespolo, R.F., Solano-Iguaran, J.J., Paleo-Lopez, R., Quintero-Galvis, J.F., Cubillos, F.A., and Bozinovic, F. (2020a). Performance, genomic rearrangements, and signatures of adaptive evolution: Lessons from fermentative yeasts. Ecol Evol 10 , 5240-5250.

Nespolo, R.F., Villarroel, C.A., Oporto, C.I., Tapia, S.M., Vega-Macaya, F., Urbina, K., De Chiara, M., Mozzachiodi, S., Mikhalev, E., Thompson, D., et al. (2020b). An Out-of-Patagonia migration explains the worldwide diversity and distribution of Saccharomyces eubayanus lineages. PLoS Genet 16 , e1008777.

Nguyen, L.T., Schmidt, H.A., von Haeseler, A., and Minh, B.Q. (2015). IQ-TREE: a fast and effective stochastic algorithm for estimating maximum-likelihood phylogenies. Mol Biol Evol 32 , 268-274.

Nova, M.X.V., Schuler, A.R.P., Brasileiro, B.T.R.V., and Morais, M.A. (2009). Yeast species involved in artisanal cachaça fermentation in three stills with different technological levels in Pernambuco, Brazil. Food Microbiology 26, 460-466.

Ortiz., E.M. (2019). vcf2phylip v2.0: convert a VCF matrix into several matrix formats for phylogenetic analysis. (Zenodo.https://doi.org/10.5281/zenodo.2540861).

Parts, L., Batte, A., Lopes, M., Yuen, M.W., Laver, M., San Luis, B.J., Yue, J.X., Pons, C., Eray, E., Aloy, P., et al. (2021). Natural variants suppress mutations in hundreds of essential genes. Mol Syst Biol 17 , e10138.

Passer, A.R., Coelho, M.A., Billmyre, R.B., Nowrousian, M., Mittelbach, M., Yurkov, A.M., Averette, A.F., Cuomo, C.A., Sun, S., and Heitman, J. (2019). Genetic and Genomic Analyses Reveal Boundaries between Species Closely Related to Cryptococcus Pathogens. mBio 10 .

Patterson, N., Price, A.L., and Reich, D. (2006). Population structure and eigenanalysis. PLoS Genet 2 , e190.

Peakall, R., and Smouse, P.E. (2012). GenAlEx 6.5: genetic analysis in Excel. Population genetic software for teaching and research-an update. Bioinformatics 28 , 2537-2539.

Pembleton, L.W., Cogan, N.O., and Forster, J.W. (2013). StAMPP: an R package for calculation of genetic differentiation and structure of mixed-ploidy level populations. Mol Ecol Resour 13 , 946-952.

Pereira, L.F., Costa, C.R.L., Brasileiro, B., and de Morais, M.A. (2011). Lachancea mirantina sp. nov., an ascomycetous yeast isolated from the cachaca fermentation process. Int J Syst Evol Microbiol61, 989-992.

Peter, J., De Chiara, M., Friedrich, A., Yue, J.X., Pflieger, D., Bergstrom, A., Sigwalt, A., Barre, B., Freel, K., Llored, A., et al. (2018). Genome evolution across 1,011 Saccharomyces cerevisiae isolates. Nature 556 , 339-344. 
Peter, J., and Schacherer, J. (2016). Population genomics of yeasts: towards a comprehensive view across a broad evolutionary scale. Yeast33, 73-81.

Pfeifer, B., Wittelsburger, U., Ramos-Onsins, S.E., and Lercher, M.J. (2014). PopGenome: an efficient Swiss army knife for population genomic analyses in R. Mol Biol Evol 31 , 1929-1936.

Pfliegler, W.P., Horvath, E., Kallai, Z., and Sipiczki, M. (2014). Diversity of Candida zemplinina isolates inferred from RAPD, micro/minisatellite and physiological analysis. Microbiol Res169 , 402-410.

Phaff, H.J., Miller, M.W., and Shifrine, M. (1956). The taxonomy of yeasts isolated from Drosophila in the Yosemite region of California. Antonie Van Leeuwenhoek 22, 145-161.

Piskur, J., Rozpedowska, E., Polakova, S., Merico, A., and Compagno, C. (2006). How did Saccharomyces evolve to become a good brewer? Trends Genet 22 , 183-186.

Ponce JF, and M., F. (2014). Climatic and Environmental History of Isla de los Estados, Argentina.

Porter, T.J., Divol, B., and Setati, M.E. (2019a). Investigating the biochemical and fermentation attributes of Lachancea species and strains: Deciphering the potential contribution to wine chemical composition. Int J Food Microbiol 290 , 273-287.

Porter, T.J., Divol, B., and Setati, M.E. (2019b). Lachancea yeast species: Origin, biochemical characteristics and oenological significance. Food Res Int 119, 378-389.

Ramasamy, R.K., Ramasamy, S., Bindroo, B.B., and Naik, V.G. (2014). STRUCTURE PLOT: a program for drawing elegant STRUCTURE bar plots in user friendly interface. SpringerPlus 3 , 431.

Rambaut, A., Drummond, A.J., Xie, D., Baele, G., and Suchard, M.A. (2018). Posterior Summarization in Bayesian Phylogenetics Using Tracer 1.7. Syst Biol 67, 901-904.

Romano, P., and Suzzi, G. (1993a). Higher alcohol and acetoin production by Zygosaccharomyces wine yeasts. Journal of Applied Bacteriology 75 , 541-545.

Romano, P., and Suzzi, G. (1993b). Potential use for Zygosaccharomyces species in winemaking. Journal of Wine Research 4, 87-94.

Ruderfer, D.M., Pratt, S.C., Seidel, H.S., and Kruglyak, L. (2006). Population genomic analysis of outcrossing and recombination in yeast. Nat Genet $38,1077-1081$.

Sampaio, J.P., and Goncalves, P. (2008). Natural populations of Saccharomyces kudriavzevii in Portugal are associated with oak bark and are sympatric with S. cerevisiae and S. paradoxus. Appl Environ Microbiol 74 , 2144-2152.

Team, R.D.C. (2008). R: A Lenguage and Environment for Statisctical Computing. R Foundation for Statistical Computing.

Tzanetakis, N., Hatzikamari, M., and Litopoulou-Tzanetaki, E. (1998). Yeasts of the surface microflora of Feta cheese.

Vakirlis, N., Hebert, A.S., Opulente, D.A., Achaz, G., Hittinger, C.T., Fischer, G., Coon, J.J., and Lafontaine, I. (2018). A Molecular Portrait of De Novo Genes in Yeasts. Mol Biol Evol 35 , 631-645.

Vakirlis, N., Sarilar, V., Drillon, G., Fleiss, A., Agier, N., Meyniel, J.P., Blanpain, L., Carbone, A., Devillers, H., Dubois, K., et al. (2016). Reconstruction of ancestral chromosome architecture and gene repertoire reveals principles of genome evolution in a model yeast genus. Genome Res 26 , 918-932.

Van der Auwera, G.A., Carneiro, M.O., Hartl, C., Poplin, R., Del Angel, G., Levy-Moonshine, A., Jordan, T., Shakir, K., Roazen, D., Thibault, J., et al. (2013a). From FastQ data to high confidence variant calls: the Genome Analysis Toolkit best practices pipeline. Current protocols in bioinformatics 43, 11.10.11-33. 
Van der Auwera, G.A., Carneiro, M.O., Hartl, C., Poplin, R., Del Angel, G., Levy-Moonshine, A., Jordan, T., Shakir, K., Roazen, D., Thibault, J., et al. (2013b). From FastQ data to high confidence variant calls: the Genome Analysis Toolkit best practices pipeline. Curr Protoc Bioinformatics 43, 11.10.11-11.10.33.

Varela, C., Sundstrom, J., Cuijvers, K., Jiranek, V., and Borneman, A. (2020). Discovering the indigenous microbial communities associated with the natural fermentation of sap from the cider gum Eucalyptus gunnii. Sci Rep 10,14716 .

Villarreal, P., Quintrel, P.A., Olivares-Muñoz, S., Ruiz, J.I., Nespolo, R.F., and Cubillos, F.A. (2021). Identification of new ethanol-tolerant yeast strains with fermentation potential from central Patagonia. Yeast.

Weir, B.S., and Cockerham, C.C. (1984). Estimating F-Statistics for the Analysis of Population Structure. Evolution $38,1358-1370$.

Wojtatowicz, M., Chrzanowska, J., Juszczyk, P., Skiba, A., and Gdula, A. (2001). Identification and biochemical characteristics of yeast microflora of Rokpol cheese. International Journal of Food Microbiology69 , $135-140$.

Woodward, F.I., Lomas, M.R., and Kelly, C.K. (2004). Global climate and the distribution of plant biomes. Philos Trans R Soc Lond Ser B-Biol Sci359 , 1465-1476.

\section{Figures}

Figure 1. Geographic distribution and phylogeny of $\mathbf{L}$. cidri isolates. (a) World map depicting the different locations where $L$. cidri were isolated. In Chile, strains were obtained from seven sampling locations. (b) Maximum likelihood tree depicting the genetic relationships between 56 strains using 218,266 biallelic SNPs (substitution model GTR+F+ASC) and manually-rooted with L. fermentati as the outgroup.

Figure 2. Population structure of L. cidri. (a) Plot of the genomic variation distribution of $56 L$. cidri strains based on the first two components of a PCA performed using 13,275 unlinked SNPs. Each dot represents a single strain. The black arrow denotes strains from Altos de Lircay National Park (AL). (b) PCA only considering strains from Patagonia. The colored PCA reflects the grouping by location. Villarrica National Park (VI), Huilo-Huilo Biological Reserve (HH), Valdivian Coastal Reserve (VCR), Osorno Volcano (OV), Chiloé National Park (CH), and Coyhaique National Reserve (CY).(c) STRUCTURE and ADMIXTURE. An optimum $\mathrm{K}=2$ group is shown in both cases. (d) Heat map of a Co-ancestry matrix obtained using fineSTRUCTURE chunk counts. Each row and column represents an isolated color indicating genetic sharing (yellow $=$ low sharing, blue $=$ high sharing). The tree shows the clusters inferred from the co-ancestry matrix. (e) $F$ st values between localities, using the same abbreviations shown in (b) as well as Central Plateau of Tasmania (CP), Australia. (f) IBD (Isolation by distance) estimates considering seven localities of southern Chile. The density of data points is indicated by colors.

Figure 3. Species delimitation and divergence time analysis inL. cidri populations . (a) DensiTrees gathered in the Bayesian analyses using StarBEAST calculated from 13 concatenated genes. Color blocks identify distinct candidate species based on genetic groups. Values in nodes correspond to the Bayesian inference result of the species tree. CBS2959 (French reference strain), and strains from Australia (Aus), Altos de Lircay National Park (AL), Huilo-Huilo Biological Reserve (HH), and Coyhaique National Reserve (CY).(b) Estimation of the divergence time since the last common ancestor between groups. Time between (1) Australia lineage and SoAm lineage; Time between (2) Australia lineage and CBS2950. Timeline in Million's years (Ky).

Fig. 4. Phenotypic diversity across L. cidri populations. (a) Heat map depicting the phenotypic diversity in $L$. cidriobtained from growth parameter using 12 different microculture conditions. Strains are grouped by hierarchical clustering; colors indicate the lineages (Australia (Aus) and South America (SoAm)), locality (Altos de Lircay National Park (AL), Villarrica National Park (VI), Huilo-Huilo Biological Reserve $(\mathrm{HH})$, Valdivian Coastal Reserve (VCR), Osorno Volcano (OV), Chiloé National Park $(\mathrm{CH})$, Coyhaique National Reserve (CY), Central Plateau of Tasmania (CP), Australia, and France (FR)) and isolation altitude 
(high altitude (HA) and low altitude (LA)). The heat map was elaborated based on the z-score of $\mu$ max $\left(\mathrm{h}^{-1}\right)$. (b) Fitness $\left(\mu \max \mathrm{h}^{-1}\right)$ variation in $6 \% \mathrm{v} / \mathrm{v}$ ethanol. Asterisks indicate statistically-significant differences according to the t-test $\left({ }^{*} \mathrm{p}<0.05 ;{ }^{* *} \mathrm{p}<0.01 ;{ }^{* * *} \mathrm{p}<0.001 ;{ }^{* * * *} \mathrm{p}<0.0001\right)$.

\section{Data accessibility}

All new fastq sequences were deposited in the National Center for Biotechnology Information (NCBI). Sequence Read Archive under the BioProject accession number PRJNA787570 (www.ncbi.nlm.nih.gov/bioproject/787570).

\section{Supplementary Material}

\section{Supplementary Figures}

Fig. S1. (a) Frequency of isolation of L. cidri compared to the total yeast found. (b) Frequency of successful L. cidri isolation of the non-Saccharomyces yeast found.(c) $\mathrm{n}^{\circ}$ of isolates per tree host.

Fig. S2. FACS analysis of $\boldsymbol{L}$. cidri isolates. Number of cell vs propidium iodide intensity is shown. Haploid (n), diploid (2n), and tetraploid (4n). S. eubayanus strains were used as a control.

Figure S3. Genetic diversity across L. cidri populations. (a) Nucleotide diversity $(\pi)$ in Chilean (SoAm) locations and the Australian (Aus) population. (b) Nucleotide diversity $(\pi$ ) in each locality. Altos de Lircay National Park (AL), Villarrica National Park (VI), Huilo-Huilo Biological Reserve (HH), Valdivian Coastal Reserve (VCR), Osorno Volcano (OV), Chiloé National Park (CH), Coyhaique National Reserve (CY), and Central Plateau of Tasmania (CP), Australia.

Fig. S4. Principal Component Analysis of the phenotypic data . Circles surround different populations (a) and localities (b). South America population (SoAm), Australia population (Aus), Altos de Lircay National Park (AL), Villarrica National Park (VI), Huilo-Huilo Biological Reserve (HH), Valdivian Coastal Reserve (VCR), Osorno Volcano (OV), Chiloé National Park (CH), Coyhaique National Reserve (CY), Central Plateau of Tasmania (CP), Australia, and France (FR).

Fig. S5. Phenotypic diversity of SoAm L. cidri strains isolated from high and low altitude locations. (a) Fitness $\left(\mu \operatorname{max~} \mathrm{h}^{-1}\right)$ variation between Aus and SoAm population.(b) Fitness $\left(\mu \operatorname{max~h}{ }^{-1}\right)$ variation between High Altitude (HA= Altos de Lircay National Park, Villarrica National Park, Huilo-Huilo Biological Reserve, Osorno Volcano, Coyhaique National Reserve) and Low Altitude (LA= Valdivian Coastal Reserve and Chiloé National Park) isolation locations. (c) Fitness $\left(\mu \mathrm{max} \mathrm{h}^{-1}\right)$ variation between HA and LA across conditions assessed. $(*)$ indicate statistically significant differences according to the t-test $(* \mathrm{p}<0.05$; ${ }^{* *} \mathrm{p}<0.01 ;{ }^{* * *} \mathrm{p}<0.001 ; * * * * \mathrm{p}<0.0001 ; \mathrm{ns}=$ not significant $)$.

\section{Supplementary Tables}

Supplementary Table 1. List of isolates employed in this study.

Supplementary Table 2. Species delimitation models.

Supplementary Table 3. Growth media utilized in this study and their composition in semi-solid and 96-well plate phenotyping assays.

Supplementary Table 4. The number of samples obtained from each National Park.

Supplementary Table 5. Hypergeometric test results.

Supplementary Table 6. Summary of bioinformatics statistics.

Supplementary Table 7. Common and unique SNPs among populations and the reference strain CBS2950.

Supplementary Table 8. Structure selector output.

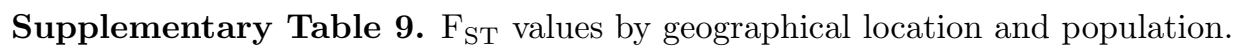


Supplementary Table 10. Summary of population genetics statistics for each clade and locality. Supplementary Table 11. Phenotype data for L. cidristrains.
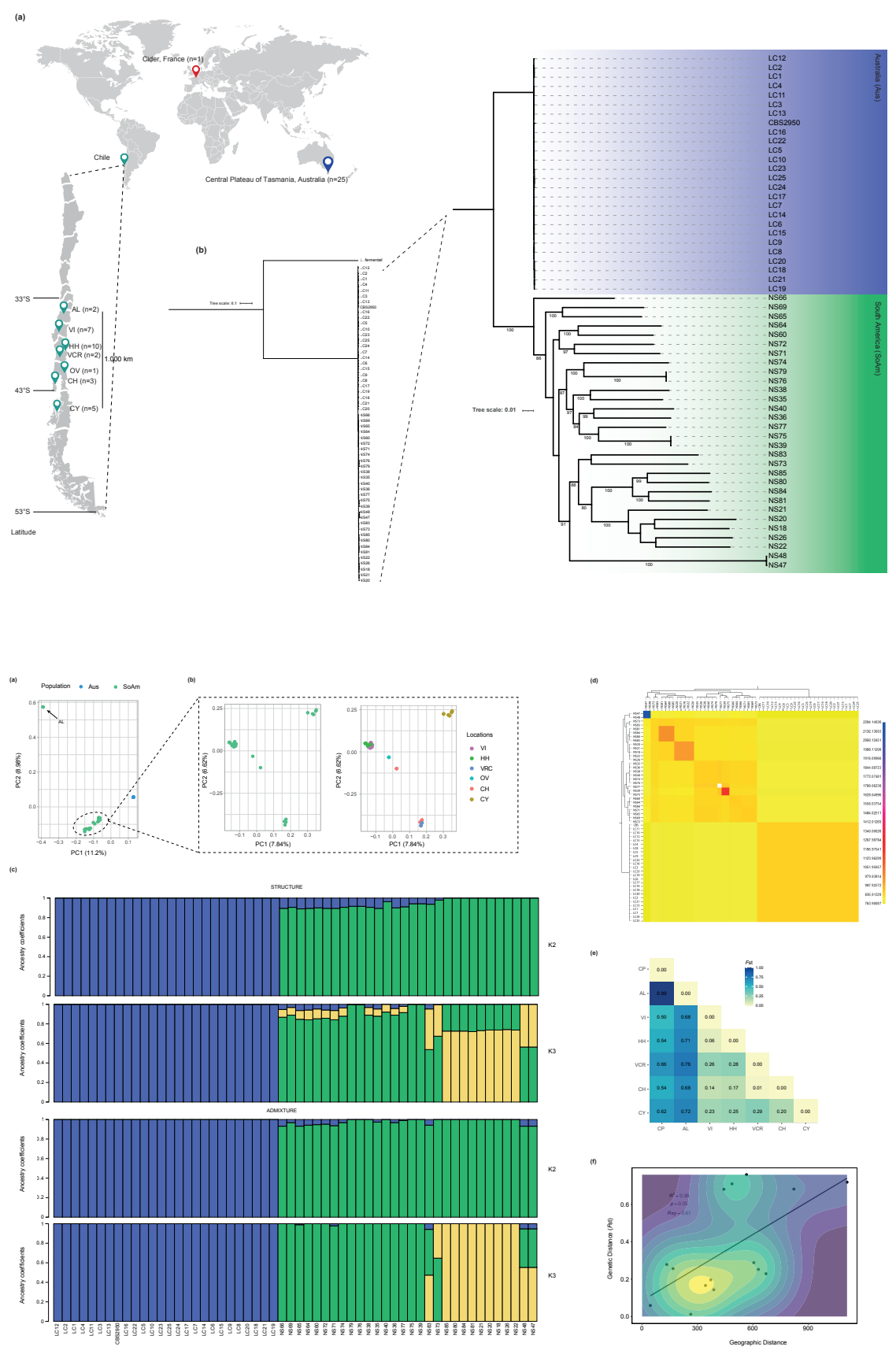
(a)

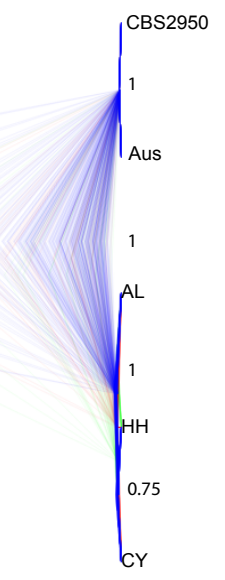

(b)

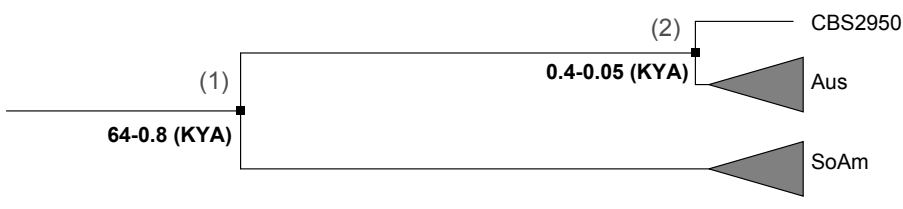

Upper Pleistocene

Holocene

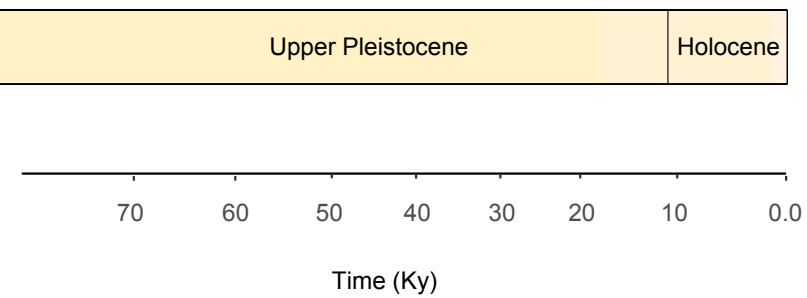



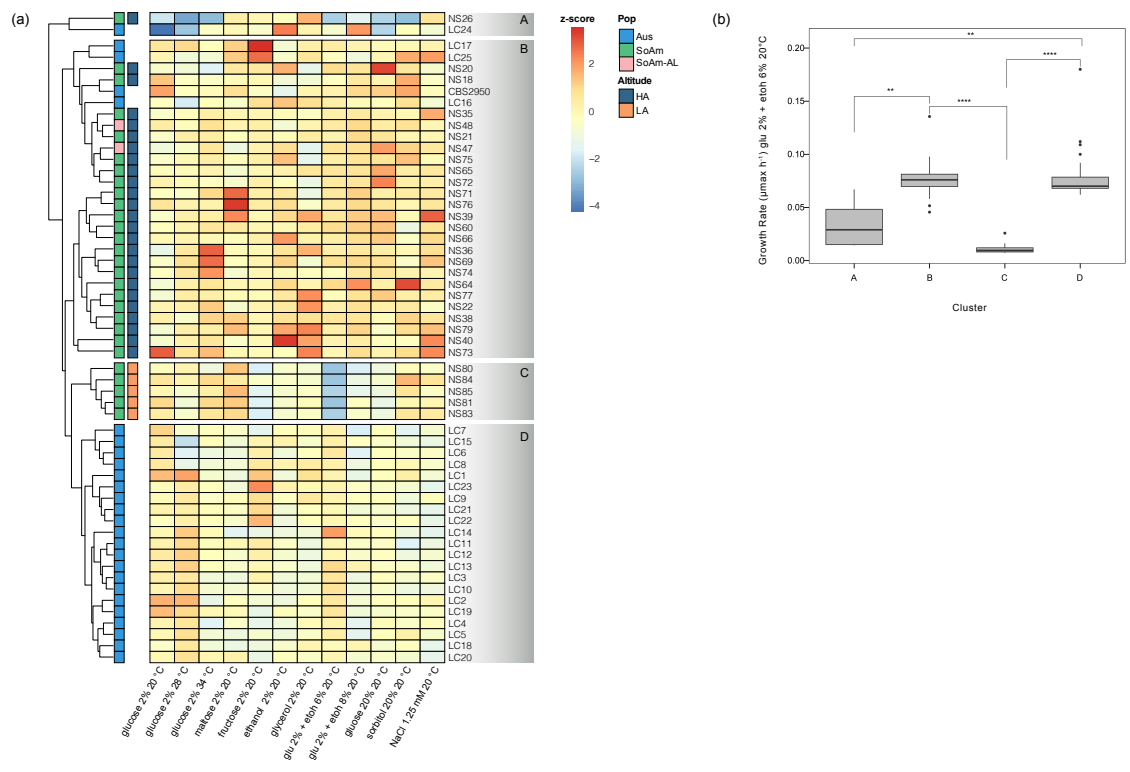

\section{Hosted file}

Supplementary_figures.pdf available at https://authorea.com/users/454801/articles/552308late-pleistocene-dated-divergence-between-south-hemisphere-populations-of-the-nonconventional-yeast-l-cidri

\section{Hosted file}

Supplementary Tables.xlsx available at https://authorea.com/users/454801/articles/552308late-pleistocene-dated-divergence-between-south-hemisphere-populations-of-the-nonconventional-yeast-l-cidri 